\title{
The Effect of Spiritual Intelligence Training on Hope in Patients with Chronic Kidney Disease Undergoing Hemodialysis: A Randomized Clinical Trial Study
}

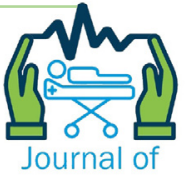

Clinical Care

and Skills

\section{ARTICLE INFO}

\section{Article Type}

Original Research

\section{Authors}

Hosseinpour S.N. ${ }^{1} M S c$,

Nooryan $\mathrm{Kh}^{2} \mathrm{MSC}$,

Abbasi Larki R. ${ }^{3} M D$

Ghafarian Shirazi H.R. ${ }^{4} P h D$,

Zoladl M.*4 $P h D$

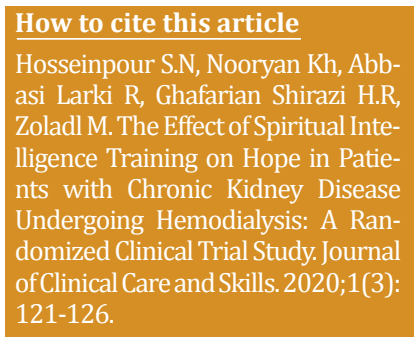

${ }^{1}$ Student Research Committee, Yasuj University of Medical Sciences, Yasuj, Iran ${ }^{2}$ Psychiatric Nursing Department, Nursing Faculty, Yasuj University of Medical Sciences, Yasuj, Iran

${ }^{3}$ Internal Medicine Department, Medicine Faculty, Yasuj University of Medical Sciences, Yasuj, Iran

${ }^{4}$ Social Determinants of Health Research Center, Yasuj University of Medical Sciences, Yasuj, Iran

\section{*Correspondence}

Address: Psychiatric Nursing Department, Nursing Faculty, Yasuj University of Medical Sciences, Dr. Jalil Street, Yasuj, Iran. Postal Code: 7591994799. Phone: +98 (74) 33235144

Fax: +98 (74) 33235144

zoladl.mohammad@yums.ac.ir

\section{Article History}

Received: November 16, 2019

Accepted:December 08, 2019

ePublished: September 21, 2020

\section{A B S T R A C T}

Aims Hemodialysis, as the most common dialysis method, is a process for removing toxins and fluids, especially uremic wastes from patients with chronic kidney disease (CKD). Repeated hemodialysis, in addition to numerous social problems, may lead to negative psychological changes, particularly lowering the hope of patients with CKD undergoing hemodialysis. The aim of this study was to determine the effect of spiritual intelligence training on hope of patients with CKD undergoing hemodialysis.

Materials \& Methods In this randomized clinical trial, 68 patients referring to the hemodialysis ward of Shahid Beheshti hospital in Yasuj, Iran in 2018 were selected by purposive sampling method and assigned into intervention and control groups via random assignment in blocks of 4 . In the intervention group, spiritual intelligence training was performed according to the considered protocol, but the control group received usual care and treatment. Research tools included the demographic information questionnaire, Integrated Spiritual Intelligence Scale (ISIS) by King, and the Snyder's hope scale. Data were analyzed by SPSS 21 software using Chi-square test, independent t-test and paired t-test.

Findings At the baseline, there was no significant difference between the intervention and control groups in terms of spiritual intelligence and hope ( $p>0.05)$. After the intervention, the hope level in the intervention group (20.82 \pm 3.21$)$ compared with the control group (18.03 \pm 3.41$)$ significantly increased $(\mathrm{p}<0.05)$.

Conclusion Spiritual intelligence training increases the hope of patients with CKD undergoing hemodialysis.

Keywords Spiritual Therapies; Hope; Patients; Chronic Kidney Disease; Hemodialysis Units, Hospital

\section{CITATION L I N K S}

[1] Perception of illness in patients undergoing ... [2] Comparison between anxiety, depression ... [3] The relationship between self-esteem and ... [4] Prevalence of chronic kidney disease in population ... [5] The multidimensional characteristics of symptoms ... [6] Iranian year view of dialysis in ... [7] Sleep quality and spiritual well-being in hemodialysis ... [8] Reasons of chronic renal failure in hemodialysis patients ... [9] Frequency of mental disturbances in hemodialysis patients ... [10] The relationship between spiritual well-being and ... [11] The effect of psychosocial group based on positive ... [12] The effect of psychosocial group based on positive ... [13] Hope: an individual motive for social ... [14] Communication skills in palliative care: a practical ... [15] Hope theory, measurements, and applications to school ... [16] The relationship between hemodialysis adequacy ... [17] Quality of life in patients with end stage renal ... [18] Mental health, depression, and anxiety in patients ... [19] Perceived social support, anxiety, and self-care among ... [20] Evaluation of depression and anxiety in hemodialysis ... [21] Depression and anxiety in patients undertaken renal ... [22] The prevalence of psychiatric illness among patients ... [23] Anxiety disorders in adults treated by hemodialysis ... [24] Spiritual care in nursing ... [25] Spiritual health; concepts and ... [26] Spirituality and intelligence: problems and ... [27] Development and determination of content and face ... [28] The effect of religiousspiritual care on anxiety ... [29] The study of the effectiveness of spiritual intelligence ... [30] Compare life expectancy and spiritual intelligence ... [31] Spiritual orientation in relation to spiritual ... [32] A survey on depression and its related factors in Nurses who ... 


\section{Introduction}

Chronic kidney disease (CKD) is a progressive and irreversible impairment of renal function that in the final stage, the kidneys are unable to maintain metabolic functions and fluid and electrolyte balance in the body, resulting in the accumulation of fluids and toxins, especially uremic products ${ }^{[1,2]}$.

Chronic kidney failure is a public health problem worldwide with the prevalence of 242 cases per million people, which is increased by $8 \%$ annually. The number of people with CKD in Iran at the beginning of 2012 was about 40,000 and it is estimated that this number will increase by $15 \%$ annually $[2,3]$.

In 2001, the average annual cost of maintenance treatment for patients worldwide was $\$ 70$ to $\$ 75$ billion, regardless of kidney transplant costs. Nowadays, with increasing incidence of CKD as well the increased prices of the medical equipment and cost of services, the medical costs of these patients have increased dramatically imposing a high burden on health care systems, especially in developing countries. Although the main treatment for CKD is kidney transplantation, hemodialysis as a life-saving treatment is the most common treatment in Iran and many countries today ${ }^{[4]}$.

At the end of 2016, about $89 \%$ of patients with CKD in the United States, China, Japan, Brazil, and Mexico were undergoing hemodialysis. In Iran, 95\% of these patients equivalent to 29,200 people had undergone hemodialysis at the end of 2016, and the growth rate of dialysis patients through this year was 4-5\% [5,6].

Previous studies have shown that although hemodialysis increases the life expectancy of patients with renal failure, but these patients are often worried about the unpredictable future of their disease and experience major lifestyle changes and depletion of quality of life. Hemodialysis is a stressful process, which can have negative effects on job and education status of the patients, because of the high cost, suffering, and the need for repetition. It can directly or indirectly causes many psychological and social problems, therefore, the hope of patients with CKD under hemodialysis is at risk [7-9]. The results of the Dehbashi et al. study indicated that the mean hope in hemodialysis patients is 17.77 on the Herth Hope Scale with a range of 12-36, which indicates a low level of hope in these patients ${ }^{[10]}$.

Hope as a positive characteristic is one of the highlevel emotions that are not present in non-human beings. It is very close to positive psychology, including people's self-assessment based on a set of criteria, one's overall desire to create the future, a kind of positive response to the perceived future, and a positive expectation to achieve the goal through planning and the will to confront obstacles $[11,12]$.

Hope has had an impact on many areas of life, and as a positive component, it affects the cognitive and emotional outcomes of individuals such as coping with stress, regulating emotional distress, increasing self-esteem, social competence, self-efficacy, and academic achievement. However, lowering hope leads to impaired cognitive-emotional functioning and may cause problems, such as depression, anxiety, and decreased psychological well-being [1315].

Patients with kidney failure experience a variety of problems due to their specific physical and mental conditions [16] and even in advanced stages, their functional status and quality of life are impaired [17]. They experience many psychiatric consequences, such as depression, anxiety, mental stress, fear of death, inability to adapt to stressful situations, personality disorders, anxiety disorders, and hopelessness $[2,7,9,18-23]$. Also, debilitating and chronic illnesses, such as chronic kidney failure pose questions about meaning and purpose in life in these patients. Many studies have identified spiritual health as a factor in creating meaning and purpose in life and enhancing the quality of life, which without it other biological, psychological, and social dimensions cannot act properly or reach their maximum capacity [24, 25]. Therefore, the promotion of spiritual intelligence in the treatment of patients with CKD under hemodialysis is of special importance.

Spiritual intelligence is the use of spiritual information to solve life's problems consistently and make sense of life and values in pursuit of goals. This type of intelligence is as a deep self-consciousness, in which the person with deep intuition becomes more aware of the dimensions of himself and with inner knowledge based on the awareness of a good understanding and unity with the universe and all its creatures and the ability to use the elements, searching meaningfulness, high alertness, and transcendence can apply the adaptation approach that produces valuable results $[26,27]$.

Considering the mentioned topics and regarding the holistic approach and the six duties done by nurses as the most important tasks for them, including of care, treatment, education, research, management and support at three levels of prevention in order to improve the physical, psychological, social and spiritual dimensions of patients' health, helping patients to find meaning, and adaptation to the disease [28], therefore, the aim of this study was to determine the effect of spiritual intelligence training on hope in patients with CKD undergoing hemodialysis.

\section{Materials and Methods}

This study was a randomized clinical trial that was performed on patients with CKD undergoing hemodialysis in 2018 referring to the hemodialysis ward of Shahid Beheshti Hospital in Yasuj, Iran. 
The samples were selected using purposive sampling method. In this way, at first 89 patients referred to the hemodialysis ward of Shahid Beheshti hospital in Yasuj, Iran were selected. After explaining the research objectives for the patients, the consent form, Integrated Spiritual Intelligence Scale (ISIS) by King, and the Snyder's hope scale were distributed among them. Of the patients, 85 cases completed a written informed consent to participate in the study. Of the subjects, 17 cases were excluded due to inclusion and exclusion criteria and 68 eligible patients were randomly assigned into intervention and control groups via random assignment in blocks of 4 .

Inclusion criteria included the age of over 15 years and passing at least three months after starting hemodialysis for CKD. Exclusion criteria included diagnosed mental illness or other chronic physical illnesses, and obtaining the scores of above 48 and 22 on the ISIS and Snyder's hope scale, respectively. The demographic and background information questionnaire to collect characteristics, such as age, sex, marital status, education level, occupation, duration of hemodialysis treatment (month), a history of other diagnosed chronic physical illnesses, and a history of diagnosed mental disorders, ISIS, and Snyder's hope scale were used as research tools. King's Integrated Spiritual Intelligence Scale (ISIS): ISIS was developed in 2008 by David King and is a 24-item scale for spiritual intelligence measuring four subscales of critical existential thinking, personal meaning production, transcendental consciousness, and expanded state of consciousness. It is scored on a five-point Likert scale: not at all true of me, not very true of me, somewhat true of me, completely true of me, very true of me. The total score of the ISIS can be between zero and 96. The cut-off score of this scale is 48 and higher scores indicate a high level of spiritual intelligence in individuals. In order to evaluate the validity of this scale, King compared it with other validated questionnaires, such as transpersonal selfconcept scale of the, the mysticism scale, the religious orientation scale (internal-external) and their correlation coefficients were $0.67,0.63$ and 0.58 , respectively. The reliability of this scale in King's studies was confirmed by Cronbach's alpha coefficient of 0.95 . Also, the reliability of this scale was confirmed by re-test in a sample of 70 individuals with a mean interval of two weeks, 0.67 and 0.89 with Cronbach's alpha coefficient [29]. In the present study, Cronbach's alpha coefficient of King's spiritual intelligence scale was 0.83 .

Snyder's hope scale: This questionnaire was developed in 1991 by Snyder et al. to measure hope. It takes 2 to $5 \mathrm{~min}$ to complete this self-administered questionnaire. The questionnaire consisted of 12 items ranging from "completely right" to "completely wrong". The items 3, 5, 7, and 11 are misleading and are not scored, but regarding the items $1,4,6$, and 8 (related to strategic sub-scale) as well as the items $2,9,10$, and 12 (related to factorial sub-scale), the item "absolutely true" is scored 4, "somewhat true" scored 3, "somewhat untrue" scored 2, "fully untrue" scored 1. To obtain the total score of this questionnaire, the total score of the questions as above is calculated and higher scores indicate more hope in the respondent. The score is ranged between 8 and 32 and a score of 22 is suggested as the cut-off point. The validity or reliability of the Snyder questionnaire as a measure of hope have been confirmed in several studies. Reliability of this scale was 0.8 through test-retest and Cronbach's alpha coefficient was reported 0.74 to 0.84 for the whole questionnaire, 0.71 to 0.76 for the factorial subscale and 0.63 to 0.8 for the strategic subscale [11, 30]. In the present study, Cronbach's alpha coefficient of the Snyder Hope Questionnaire was 0.76 .

The intervention group received eight 60-minute sessions of spiritual intelligence training, including lecture, question and answer, and practical exercise (Table 1), whereas in the control group, subjects received only usual care and treatment.

Table 1) Summary of the content of the sessions of the spiritual intelligence training protocol

First session

Introduction, expectations and rules, an introduction and a brief explanation of the intervention

Second session

Training the basics of spiritual intelligence and related exercises (1)

Third session

Training the basics of spiritual intelligence and related exercises (2)

Fourth session

Training and practicing relaxation

Fifth session

Meditation training and practice

Sixth session

Training and practicing self-awareness (1)

Seventh session

Training and practicing self-awareness (2)

Eighth session

Training and practicing critical thinking

After the intervention, King's Spiritual Intelligence Scale and the Snyder's hope scale were again completed by the subjects and the collected data were analyzed by SPSS 21 software at a 95\% confidence level.

Inter-group comparison was done by independent ttest regarding quantitative variables, including demographic and background variables, such as age and duration of hemodialysis treatment (month), the level of spiritual intelligence and the dependent variable of the level of hope that had a natural distribution. Chi-square test was used for intergroup comparison to compare the qualitative variables, including demographic and background variables, such as sex, marital status, educational level, and occupation. Paired t-test was also used to compare intra-group comparison for dependent 
variable of hope, which showed a normal distribution.

All research ethical issues, such as obtaining written informed consent from patients participating in the research, the possibility of withdrawal from the study, confidentiality of the information and using them in general and based on the research objectives, no changes in used medications, no deprivation of standard treatments and care, and no additional costs on research participants and the insurance organizations were observed. Also, considering the positive effects of spiritual intelligence training on hope in the intervention group, after preparing the final report of the research, spiritual intelligence training was conducted for the control group according to the protocol.

\section{Findings}

68 patients with chronic renal failure with a mean age of $53.32 \pm 14.76$ years and undergoing hemodialysis for $19.41 \pm 18.82$ months were studied. The mean age in the intervention and control groups was $50.94 \pm 14.08$ and $55.71 \pm 15.25$ years and the mean duration of hemodialysis was $18.38 \pm 15.60$ and $20.44 \pm 21.75$ months, respectively. There was no significant difference between the groups in terms of these quantitative variables at the baseline ( $p>0.05)$. Also, there was no significant difference between the two groups in terms of demographic and contextual variables, such as sex, marital status, educational level and occupation status ( $\mathrm{p}>0.05$; Table 2).

Table 2) The absolute and relative frequency of demographic and background variables in patients with chronic renal failure undergoing hemodialysis in the intervention $(\mathrm{N}=34)$ and control $(\mathrm{N}=34)$ groups at baseline (The numbers in parentheses are percent)

\begin{tabular}{lccc}
\multicolumn{1}{c}{ Variables } & $\begin{array}{c}\text { Intervention } \\
\text { group }\end{array}$ & $\begin{array}{c}\text { Control } \\
\text { group }\end{array}$ & P. value \\
\hline $\begin{array}{l}\text { Gender } \\
\text { Male }\end{array}$ & $19(55.9)$ & $21(61.8)$ & \\
Female & $15(44.1)$ & $13(38.2)$ & 0.62 \\
Marital status & & & \\
Single & $7(20.6)$ & $3(8.8)$ & 0.17 \\
Married & $27(79.4)$ & $31(91.2)$ & \\
Education & & & \\
Below Diploma & $19(55.9)$ & $26(76.5)$ & \\
Diploma & $6(17.6)$ & $5(14.7)$ & 0.12 \\
Above Diploma & $9(26.5)$ & $3(8.8)$ & \\
Occupation & & & \\
Unemployed & $16(47.1)$ & $13(38.2)$ & \\
Non-governmental & $1(2.9)$ & $4(11.8)$ & 0.45 \\
Employee & $7(20.6)$ & $5(14.7)$ & \\
Housewife & $10(29.4)$ & $12(35.3)$ & \\
\hline
\end{tabular}

The spiritual intelligence scores at baseline were $36.32 \pm 4.90$ and $36.38 \pm 5.33$ in the intervention and control groups, respectively. There was no significant difference between the groups in terms of spiritual intelligence at the baseline $(p>0.05)$. At the end of the study, spiritual intelligence scores in the intervention and control groups changed to $53.38 \pm 6.16$ and $48.48 \pm 5.95$, respectively, which were significantly higher in the intervention group $(\mathrm{p}<0.05)$, which confirmed the validity of spiritual intelligence training as an independent variable and its effect on the scores of the study groups.

Hope level and its subscales were similar in the intervention and control groups at baseline ( $p>0.05)$. After the intervention, hope and its subscales increased significantly in the intervention group compared to the control group $(\mathrm{p}<0.05)$. In the intra-group comparison, considering the mean difference of hope scores and its strategic and factorial subscales, patients' hope and its subscales in both intervention and control groups after the intervention compared with the baseline $(5.93 \pm 1.88$, $3.21 \pm 1.23$ and $2.72 \pm 1.30$ in the intervention group and $4.31 \pm 1.62,2.46 \pm 1.10$ and $1.85 \pm 1.32$ in control group) ( $<<0.05$; Table 3$)$.

Table 3) Comparison of mean scores of hope and its subscales at baseline and after the intervention in intervention and control groups

\begin{tabular}{|lc|c|c|}
\hline \multicolumn{1}{c}{ Variables } & $\begin{array}{c}\text { Control } \\
\text { group }\end{array}$ & $\begin{array}{c}\text { Intervention } \\
\text { group }\end{array}$ & $\begin{array}{c}\text { Inter- } \\
\text { group P. } \\
\text { value }\end{array}$ \\
\hline Hope & $13.72 \pm 3.10$ & $14.89 \pm 2.81$ & 0.11 \\
At baseline & $18.03 \pm 3.41$ & $20.82 \pm 3.21$ & 0.001 \\
After intervention & 0.0001 & 0.0001 & - \\
Intra-group P. value & & & \\
Strategic subscales & & $8.58 \pm 1.49$ & 0.13 \\
At baseline & $7.92 \pm 2.03$ & $11.79 \pm 1.89$ & 0.003 \\
After intervention & $10.38 \pm 1.91$ & 0.0001 & - \\
Intra-group P. value & 0.0001 & & \\
Factorial subscales & & & 0.26 \\
At baseline & $5.80 \pm 1.89$ & $6.31 \pm 1.76$ & 0.01 \\
After intervention & $7.65 \pm 2.35$ & $9.03 \pm 1.90$ & - \\
Intra-group P. value & 0.0001 & 0.0001 & - \\
\hline
\end{tabular}

\section{Discussion}

The findings of the present study indicated that the intervention and control groups at the baseline were homogenized regarding quantitative and qualitative demographic and background variables, as well as the level of spiritual intelligence and hope and their subscales. Therefore, changes in hope after intervention in patients with CDK undergoing hemodialysis were due to the effect of spiritual intelligence training as an independent variable.

After the intervention, the total score of spiritual intelligence in the intervention group was significantly higher than the control group. It indicates that spiritual intelligence training was effective in increasing the spiritual intelligence of patients undergoing hemodialysis in the intervention group and confirms the validity of spiritual intelligence training as an independent variable of the study. The findings of the present study are in line with the results of Mohammadi and Rahnama research, which showed that spiritual intelligence training increases spiritual intelligence in dialysis patients [29].

The results of this study showed that after the intervention, hope and its subscales were 
significantly increased in the intervention group compared to the control group. Therefore, it can be concluded that spiritual intelligence training as the research intervention was able to differentiate between the intervention and control groups and significantly increased hope and its subscales in patients with CKD undergoing hemodialysis in the intervention group. Therefore, the effect of training the components of spiritual intelligence on increasing the level of hope in patients with CKD undergoing hemodialysis is confirmed.

The findings of studies by Snyder et al. [13, 15], Nasel [31], Mauk and Schmidt [24], Omidvari [25], Eslami et al. [7] and Dehbashi et al. [10] support the findings of the present study indicating a significant increase in hope by spiritual intelligence training in patients with CKD undergoing hemodialysis. The findings of the present study are also reasonable and justified in the hope changes based on theoretical knowledge, because spiritual intelligence is linked to the individual's important structures in his life, and since it helps one to cope with life's problems through increasing meaning and purpose in life, therefore, spiritual intelligence training was effective in increasing the hope of patients with CKD undergoing hemodialysis.

The intra-group comparison of hope showed that in intervention group, overall level of hope and its strategic and factorial sub-scales after research intervention were significantly increased compared to the baseline. The control group also had a slight significant increase in total score of hope and its strategic and factorial sub-scales after research intervention compared to the baseline. To explain and justify a slight increase in hope level in the control group in intra-group comparison, in addition to the probability of sampling error, the familiarity of the control group with the relevant questions in the pre-test, the possible impact of the training provided to the patients in the intervention group, and obtaining relevant information from other sources can be mentioned.

Due to the positive therapeutic effects of spiritual intelligence training in increasing the hope of patients with CKD undergoing hemodialysis in this study, and also the availability, cost-effectiveness, efficacy rate, and minor side effects of this intervention, therefore, after confirming the results by other relevant studies, spiritual intelligence training can be used as a complementary therapy in the treatment of patients with CKD undergoing hemodialysis.

Accordingly, since nurses are the most populated and accessible part of the professional care team providing health, care, support and education services at three levels of prevention [32], Therefore, researchers suggest that spiritual intelligence and its application in patients with CKD undergoing hemodialysis should be considered in nursing educational headlines and courses.
The present study also had some limitations affecting the results of the study. In this study, patients in the intervention group were advised to avoid transferring educational contents to other patients or asking questions about content learned from individuals other than the main researcher. However, the possible conversation of the patients in the intervention and control group while connecting to the hemodialysis machine and the possibility of exchange of information between them regarding educational contents and exercises could affect the results of the study. Also, although the subjects were asked not to participate in other educational or psychological interventions or obtaining information during through the research, but it might have been ignored by the intervention and control groups, which might have affected the results of the study. Hence, it is necessary to consider the limitations while analysis the results of this study.

Patients undergoing hemodialysis also experience negative complications, such as depression, anxiety, stress, fear of death, etc. Therefore, it is recommended investigating the effect of spiritual intelligence training on these variables in patients with CKD undergoing hemodialysis in future studies. Also, considering the chronic nature of CKD and the positive impact of spiritual intelligence training on hope in these patients, it is suggested to examine the impact of spiritual intelligence training on the psychological consequences of other chronic and life-threatening diseases.

\section{Conclusion}

Spiritual intelligence training increases the hope of patients with CKD undergoing hemodialysis and is effective in increasing hope and consequently mental health of patients with CKD undergoing hemodialysis as an adjunctive therapy.

Acknowledgments: This study was extracted from a research approved by the Research Council of Yasuj University of Medical Sciences. The authors are grateful to the staff of the School of Nursing and the Vice Chancellor for Research and Technology of Yasuj University of Medical Sciences, the staff of the Hemodialysis ward of Shahid Beheshti Hospital affiliated to the Yasuj University of Medical Sciences, the patients who participated in the study and all those who contributed to this study.

Ethical Permission: This study was approved by the Research Ethics Committee of Yasuj University of Medical Sciences (IR.YUMS.REC.1397.046) and registered at the Iranian Registry of Clinical Trials (IRCT20180522039783N1).

Conflict of interests: There is no conflict of interests.

Authors' Contribution: Hosseinpour SN. (First author), Introduction author/ Original researcher/ Discussion author (20\%); Nooryan K. (Second author), Methodologist/ Assistant (10\%); Abbasi Larki R. (Third author), Introduction author/ Assistant (10\%); Ghafarian Shirazi HR. (Fourth author), Statistical analyst/ Assistant (10\%); Zoladl M. (Fifth author), Introduction author/ 
Original researcher/ Methodologist/ Statistical analyst/ Discussion author (50\%)

Funding: The Vice of Research and Technology of the Yasuj University of Medical Sciences funded this research.

\section{References}

1- Saeedi M, Ghafarzadeghan R, Hekmatpou D. Perception of illness in patients undergoing hemodialysis: a qualitative study. Iran J Nurs. 2017;30(108):60-71. [Persian]

2- Mollahadi M, Tayyebi A, Ebadi A, Daneshmandi M. Comparison between anxiety, depression and stress in hemodialysis and kidney transplantation patients. Iran J Crit Care Nurs. 2010;2(4):153-6. [Persian]

3- Rezaei L, Salehi S. The relationship between selfesteem and coping styles in patients undergoing hemodialysis. Int J Med Res Health Sci. 2016;5(7S):1-6.

4- Zhang QL, Rothenbacher D. Prevalence of chronic kidney disease in population-based studies: systematic review. BMC Public Health. 2008;8:117.

5- Jablonski A. The multidimensional characteristics of symptoms reported by patients on hemodialysis. Nephrol Nurs J. 2007;34(1):29-37.

6- Iranian Consortium of dialysis. Iranian year view of dialysis in 2016. $1^{\text {st }}$ Edition. Tehran: International affair of Iranian Consortium of dialysis; 2017. [Persian]

7- Eslami AA, Rabiei L, Khayri F, Rashidi Nooshabadi MR, Masoudi R. Sleep quality and spiritual well-being in hemodialysis patients. Iran Red Crescent Med J. 2014;16(7):e17155.

8- Monfared A, Khosravi M, Orang poor R, Moosavian Roshanzamir S, Aghajani Nargesi D. Reasons of chronic renal failure in hemodialysis patients in Guilan Province. J Guilan Univ Med Sci. 2003;12(46):76-83. [Persian]

9- Navidian A, Arbabi Sarjou A, Keikhai A. Frequency of mental disturbances in hemodialysis patients referred to hemodialysis ward of Khatam- Al- Anbia Hospital in Zahedan. J Guilan Univ Med Sci. 2006;15(58):61-7. [Persian]

10- Dehbashi F, Sabzevari S, Tirgari B. The relationship between spiritual well-being and hope in Hemodialysis patients referring to the Khatam Anbiya hospital in Zahedan 2013-2014. Med Ethics J. 2015;8(30):77-96. [Persian]

11- Abdeyan T, Khoram Kish M, Zoladl M, Ghafarian Shirazi HR, Nooryan K. The effect of psychosocial group based on positive psychology on hopefulness in patients with major depressive disorder: a clinical trial. Electron J Gen Med. 2018;15(3):em49.

12- Shehni-Yailagh M, Kianpour Ghahfarkhi F, Maktabi G, Neasi A, Samavi A. Reliability and validity of the Hope scale in the Iranian students. J Life Sci Biomed. 2012;2(4):125-8.

13- Snyder C, Cheavens J, Sympson SC. Hope: an individual motive for social commerce. Group Dyn. 1997;1(2):107-18.

14- Buckman R. Communication skills in palliative care: a practical guide. Neurol Clin. 2001;19(4):989-1004.

15- Snyder CR, Lopez SJ, Shorey HS, Rand KL, Feldman DB. Hope theory, measurements, and applications to school psychology. Sch Psychol Q. 2003;18(2):122-39.
16- Ashrafi Z, Ebrahimi H, Sarafha J. The relationship between hemodialysis adequacy and quality of life and spiritual wellbeing in hemodialysis patients. J Clin Nurs Midwifery. 2014;3(3):44-51. [Persian]

17- Rambod M, Rafiei F, Hosseini F. Quality of life in patients with end stage renal disease. Hayat. 2008;14(2):51-61. [Persian]

18- Feroze U, Martin D, Reina-Patton A, Kalantar-Zadeh K, Kopple JD. Mental health, depression, and anxiety in patients on maintenance dialysis. Iran J Kidney Dis. 2010;4(3):173-80.

19- Mollaoglu M. Perceived social support, anxiety, and self-care among patients receiving hemodialysis. Dialysis Transplant. 2006;35(3):144-55.

20- Nazemian F, Ghafari F, Pourghazneyn T. Evaluation of depression and anxiety in hemodialysis patients. Med J Mashhad Univ Med Sci. 2008;51(3):171-6. [Persian]

21- Masoudi Alavi N, Sharifi K, Aliakbarzadeh Z. Depression and anxiety in patients undertaken renal replacement therapy in Kashan during 2008. Feyz J. 2009;12(4):46-51. [Persian]

22- Farmer C, Snowden S, Parsons V. The prevalence of psychiatric illness among patients on home haemodialysis. Psychol Med. 1979;9(3):509-14.

23- Cukor D, Coplan J, Brown C, Friedman S, Newville H, Safier M, et al. Anxiety disorders in adults treated by hemodialysis: a single-center study. Am J Kidney Dis. 2008;52(1):128-36.

24- Mauk KL, Schmidt NA. Spiritual care in nursing practice. Philadelphia: Lippincott Williams \& Wilkins; 2004.

25- Omidvari S. Spiritual health; concepts and challenges. Quran Interdiscip Stud J. 2009;1(1):5-17. [Persian] 26- Emmons RA. Spirituality and intelligence: problems and prospects. Int J Psychol Relig. 2000;10(1):57-64.

27- Khodayarifard M, Khorami Markani A, Ghobari Bonab B, Sohrabi F, Zamanpour E, Raghebian R, et al Development and determination of content and face validity of spiritual intelligence scale in Iranian students. Appl Psychol Res Q. 2017;7(4 ):39-49. [Persian]

28- Tajbakhsh F, Hosseini MA, Sadeghi Ghahroudi M, Fallahi Khoshkenab M, Rokofian A, Rahgozar M. The effect of religious-spiritual care on anxiety post surgery coronary artery bypass graft patients. Iran J Rehabil Res Nurs. 2014;1(1):51-61. [Persian]

29- Mohammadi A, Rahnama P. The study of the effectiveness of spiritual intelligence training on the life expectancy and psychological well-being of dialysis patients in Tehran. J New Res Hum Sci. 2016;2(2):195225. [Persian]

30- Moghtader L. Compare life expectancy and spiritual intelligence in breast cancer and healthy women. J Guilan Univ Med Sci. 2017;26(101):58-65. [Persian]

31- Nasel D. Spiritual orientation in relation to spiritual intelligence: a consideration of traditional Christianity and New Age/individualistic spirituality [Dissertation]. Adelaide SA: University of South Australia; 2004.

32- Dehghani M, Zoladl M, Boland-Parvaz S, Keshtkaran Z, Mahmoudi R, Jabbarnejad A. A survey on depression and its related factors in Nurses who work in Namazi Hospital of Shiraz University of Medical Sciences-2008. Iran Occup Health J. 2009;6(3):24-31. [Persian] 